\title{
Congenital megacalyces
}

\author{
J. Michael Zerin
}

Received: 5 March 2010 /Accepted: 10 March 2010/Published online: 30 April 2010

(C) Springer-Verlag 2010

In this issue, Bekele and Sanchez [1] illustrate an interesting case of congenital megacalyces (CM) that was first detected prenatally. As they note, $\mathrm{CM}$ is a rare developmental disorder of the renal medulla that produces nonprogressive, nonobstructive calyceal dilatation and distortion with supernumerary calyces and medullary hypoplasia. The classic urographic findings of a large kidney with polycalycosis and polygonal calyces with narrow infundibula are usually straightforward. On the other hand, sonographic differentiation from either obstructive or nonobstructive pelvocaliectasis can be considerably more challenging. In addition, the presence of polycalycosis is more difficult to recognize on US than on urography.

J. M. Zerin $(\bowtie)$

Department of Pediatric Imaging,

Children's Hospital of Michigan,

3901 Beaubien Blvd.,

Detroit, MI 48201, USA

e-mail: jzerin@dmc.org

\section{J. M. Zerin}

Department of Radiology,

Wayne State University School of Medicine,

Detroit, MI, USA
Bekele and Sanchez [1] rightly describe the findings of irregular calyceal distention with nondilated infundibula and renal pelvis on US, findings that are characteristic of $\mathrm{CM}$. They are also correct in suggesting that $\mathrm{CM}$ should be included in the differential diagnosis of unusual-appearing caliectasis in neonates and children, particularly when there are suggestive associated findings. However, given the marked rarity of $\mathrm{CM}$ and the extremely common occurrence, variable severity, and often nonprogressive nature of neonatal hydronephrosis, it is uncertain how reliable US would be in differentiating the two disorders. Moreover, obstructive uropathy can occasionally coexist with $\mathrm{CM}$, whether due to congenital UPJ or UVJ obstruction or to complicating stone disease. I have also seen progressive hydroureteronephrosis in a child with bilateral CM who had coexistent myelomeningocele with neurogenic bladder.

Although I would never go back, it is worthwhile considering what this case might show us about what we gave up in addition to what we gained when we made the transition from urography to US.

\section{References}

1. Bekele W, Sanchez TR (2010) Congenital megacalyces presenting as neonatal hydronephrosis. Pediatr Radiol 40. doi:10.1007/ s00247-010-1646-2 